\title{
Effects of stimulus transiency in a contingent discrimination situation
}

MYMON GOLDSTEIN, RONNIE S. RAPPAPORT, AND DENNIS W. SCHAEFER, DEPARTMENT OF PSYCHOLOGY, LONG ISLAND UNIVERSITY, Brooklyn, N.Y.

Correct alternatives were aetermined by recurrent and/or transient auxiliary stimuli in a two-choice situation administered to humans. One of two transiency treatments proved more difficult than the recurrence treatments.

When stimuli are substituted successively in a role related to discrimination learning, it is sometimes found that humans handle the situation well (e.g., Goldstein \& Fleming, 1967) but more often they seem to be handicapped by the absence of a recurrent stimulus in that role (e.g., Goldstein \& Wright, 1966). This issue of transiency vs recurrence is studied here for the first time in connection with a contingent discrimination paradigm like that of Goldstein \& Weber (1965).

Method

The contingent discrimination paradigm used by Goldstein \& Weber (1965) corresponded to the display sequence for Group R1 in Fig. 1. A single pair of alternatives was offered for choice on every display, but occurred equally often in both possible positional arrangements. Contingent identity methodology was applied, i.e., one of two possible auxiliary stimuli appeared above

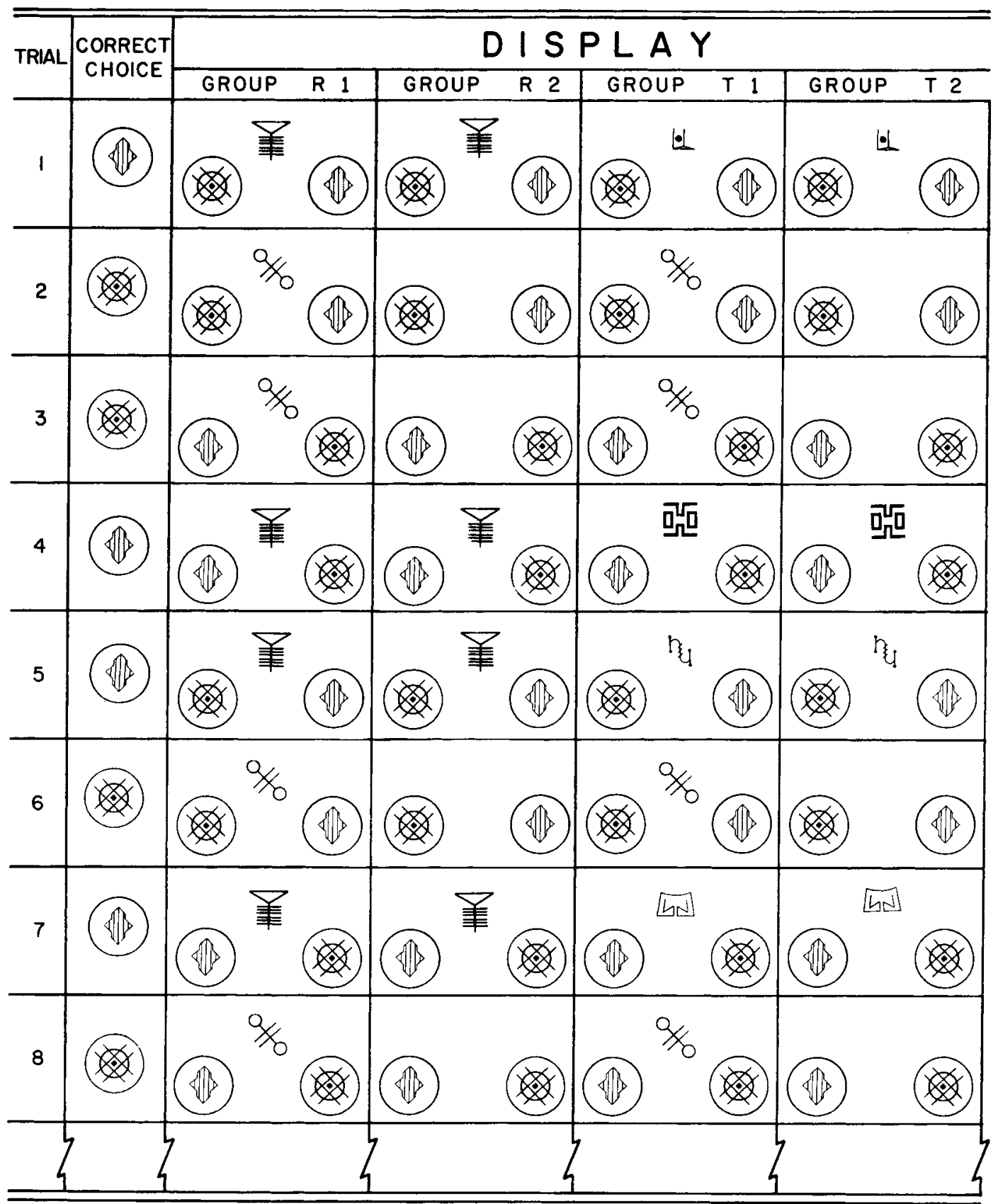

Fig. 1. Displays and correct alternatives for the four experimental groups on Trials 1 to 8 . There were 272 trials in all. 
Table 1

Frequencies Reaching Criterion and Error Data for Those Reaching Criterion

\begin{tabular}{lcccc} 
& \multicolumn{5}{c}{ Group } \\
\cline { 2 - 5 } & R1 & R2 & T1 & T2 \\
\hline $\mathrm{N}$ & 11 & 9 & 10 & 12 \\
n (reached criterion) & 9 & 8 & 9 & 8
\end{tabular}

Errors to criterion

(n only)

$\begin{array}{lllll}\text { M } & 24.0 & 18.5 & 27.7 & 54.9 \\ \text { SD } & 26.6 & 25.4 & 31.5 & 25.5\end{array}$

the alternatives, and each auxiliary stimulus indicated that a different one of the alternatives was correct. The display sequence for Group R2 was obtained by dropping one of the auxiliary stimuli, so that absence of an auxiliary stimulus had cue value as in the related, but different study of Goldstein \& Galef (1965). The other auxiliary stimulus provided the basis for a transiency treatment, and was replaced by a succession of never-repeated stimuli in Groups T1 and T2. This transiency treatment was the reason for the experiment's being, and is therefore featured in the group nomenclature, which contrasts $R$ with $T$ to signify recurrence vs transiency. In all respects other than transiency, Group T1 corresponded to Group R1 and Group T2 to Group R2, so that the correct choice was the same for all groups on any given trial. Note, too, that all groups faced the same positional arrangement of the alternatives offered for choice on any given trial. Figure 1 shows only the start of the experiment, which terminated at 272 trials.

The $S$ encountered his display sequence as a stack of 272 cards mounted on an arch binder. He turned the cards himself and made choices by pointing. E said "correct" or "wrong" and produced a record of responses. The instructions indicated only that $S$ should try to maximize the number of correct choices and never choose a stimulus appearing at the top. There was no time limit.

The Ss were 42 undergraduates at Long Island University. They were distributed unequally over the four experimental groups, whose sizes are reported in Table 1 .

Results and Discussion

The obtained data revealed a striking difference in difficulty between the display sequence presented to Group T2 and the display sequences presented to the remaining three groups. Group T2 was least successful; the other groups performed at roughly comparable levels. An overview of the experiment is provided by Table 1 , which is based on a criterion of 20 consecutive correct responses. There were eight failures to reach criterion in the experiment, and four of them were in Group T2 alone. Among Ss that did reach criterion, error means were much larger for Group T2 than for the other groups. A median test applied to the error data for all 42 Ss yielded a chi-square value significant at the .01 level, whose large size resulted mainly from the deviant character of Group T2. Stimulus transiency was clearly a source of difficulty, but only in a bizarre way that flatly contradicts the implications of the Goldstein \& Galef (1965) study which would lead one to expect Group T1 to encounter more difficulty than Group T2 or perhaps an equal amount, but certaintly not less: It therefore seems most reasonable to view the result as a main effect rooted in transiency vs recurrence rather than as an interaction meaningfully related to the difference in treatment between Group T1 and Group T2.

The error means in Table 1 omit post-criterion errors, which were exhibited by $50 \%$ of the Ss reaching criterion and involved no apparent intergroup differences. There were 38 such errors altogether, and that amounts to a mean of 1.1 post-criterion errors for all Ss reaching criterion.

\section{REFERENCES}

GOLDSTEIN, M., \& FLEMING, J. M. Absence of transfer in a family of similar tasks. Percept. mot. Skills, 1967, 25, 909-912.

GOLDSTEIN, M., \& GALEF, B. G. Absolute and differential cuing of successive reversals. Percept. mot. Skills, 1965, 21, 159-166.

GOLDSTEIN, M., \& WEBER, R. J. Contingent discrimination in humans. Percept. mot. Skills, 1965, 21, 171-176.

GOLDSTEIN, M., \& WRIGHT, P. D. An uncomplicated but difficult two-part learning set task. Psychon. Sci, 1966, 6, 479-480. 